\title{
A Brief History of Human Ecology within the Ecological Society of America and Speculation on Future Direction
}

\author{
Section Editor: Robert Dyball
}

The relationship of knowledge, including scientific knowledge, to improved policy and decision-making is a vexed one (Fischer et al., 2012, p. 8). Like any other organization of significance in its field, the Ecological Society of America (ESA) has, throughout its history, hoped both to contribute to the accumulation of knowledge and to influence policy and public opinion. In a recent editorial in the society's premier journal, Frontiers in Ecology, Jane Lubchenco (2017) argued for the need to make "scientific information understandable, credible, relevant, and accessible to help inform (not dictate) decisions" (p. 3). Yet, there is an unavoidable tension between the ambition to be a "proper science" whose object of study is all things ecological and the goal of influencing change to make the world a better place. Human ecology has long existed as a subfield within ESA. Its ability to contribute, or not, to ESA's ambitions to influence policy in relation to the pressing problems of the day has been constrained by two related issues: how these problems have been framed, and the role and best mode of science for informing policy directed at resolving these problems. For as long as these problems have been interpreted as the consequence of humans "interference in nature," and for as long as the mode of science deemed most appropriate for informing policy change has been quantitative data-based "objective" descriptions of change in ecological processes, the ability of human ecology to contribute to resolving these problems has been constrained. A brief history of this tension is laid out here, with some speculation on how recent moves to reinterpret both the nature of today's problems and the most appropriate mode of science for informing policy to help manage those problems may allow human ecology to contribute in new ways.

The story of human ecology within ESA can be told as the tale of two sciences. The first, running on and off through the first decades of ESA's existence, was an attempt to form an applied problem-solving science studying the nature of human influences on ecological processes as a new sub-discipline within the broader discipline of ecology. This endeavor failed, or at least it "failed to materialize as a consistent and coherent field of inquiry" (Cittadino, 1993, p. 253). The suggestion made here is that this failure stemmed, at least in part, from a trend toward ever-narrower specializations within ecology, resulting in what Worster (1977) called a "cacophony of subfields" (p. 340). This fracturing would have been antithetical to what was recognized at the time as the inherently synthetic nature of human ecology. Further, 
a scientific methodology that generates knowledge by decomposing complex systems into ever-smaller parts is ill-suited to understanding human ecological interactions. Thus, while human ecology continued throughout the second half of last century, it did so without formal recognition by ESA. The greater success of the recent re-activation of human ecology within ESA depends on human ecology developing a scientific mode more suited to the phenomenon it seeks to study, and whether this mode of science can be regarded as legitimate by other ecologists. Some general characteristics of such a science have been proposed under the name "post-normal science" (Funtowicz \& Ravetz, 1991; Ravetz, 1997, 2006).

Despite Ellen Swallow Richard's hopes that ecology be understood as essentially human ecology from the beginning, as the "science of the conditions of the health and well-being of everyday human life" (Dyball \& Carlsson, this volume), history records that it was originally conceived as a sub-branch of biology. The earliest formal definition seems to be that ecology is "the exploration ${ }^{1}$ of the endless phenomena of animal and plant life as they manifest themselves under natural conditions" (Sanderson, 1893, p. 613). Many would take the word "natural" to exclude "human." ESA was originally understood as being concerned with the two main sub-branches of biology—botany and zoology—distinguished primarily by an emphasis on fieldwork (Burgess, 1977). ESA's first president, the zoologist Victor Shelford (1917), ${ }^{2}$ added emphasis to the interrelational aspect of ecology, saying:

While primarily concerned with the physiological relations of organisms to environment, and while tending to become to a marked degree an experimental science, the workers in the field have thus far derived, and probably will always derive, their inspiration from the dynamic relations of organisms to their environment. (p. 1)

In this ecology, humans manifest primarily as disturbers of nature-as Borden (this volume) notes, Shelford was an "avid conservationist." One of the first committees ESA established, in 1917, was for the "Preservation of Natural Conditions for Ecological Study" (Burgess, 1977, p. 13). However, the society did not exclude studies of humans in their use of environmental resources, with forestry and agriculture both present as disciplinary subfields in the inaugural handbook (Burgess, 1977, p. 4).

With time, ESA was to grow increasingly interested in the effect of humans' behavior on their environments and, in turn, the effect environments have on them. "Human ecology" started to be used as a term for this sub-area of concern from the late 1920s, with ESA founding member Charles ("Chas") Adams writing on the "Relation of General Ecology to Human Ecology" in 1935. At this time, ecology was well

1 In his biography of Ellen Swallow Richards, Clarke (1973) misquotes this as "exploitation" (p. 154).

2 A paper on Victor Shelford was given in the ESA conference session, but could not be included in this special issue. 
advanced in its efforts to establish itself as a bona fide science by establishing lawlike principles that could be applied to its field of study to account for its behavior. Adams (1935) wrote that ecology deals with:

The causes and laws of change in the environment and in organisms, distinguishing the energies involved, the activities of the agents or the systems, their dynamic status, their relative optima, limiting factors and the orderly sequence or succession of their internal and external changes. (p. 319, emphasis in original)

In Adams's view, human ecology's contribution was to understand the effect humans have on the dynamics of the processes driving these "laws of succession" and, in turn, the effect these dynamics have on humans and their cultures. For example, he argued that where different ecotones produce different levels and a diversity of biological resources, this creates a sociocultural need for humans to adapt and differentiate to appropriate those resources. In time, this sociocultural heterogeneity, and the uneven wealth of resources, creates pressures, competition, and friction between groups. Social sciences such as archaeology and history can contribute insight into these processes of sociological succession, seen as equivalent to, and interrelated with, the process of ecological succession. Adams saw the role of human ecology as to sit within ecology, but also cross into those social sciences that explain human social interactions with, and social responses to, ecological processes.

Clearly, there was a sense that the reciprocal interactions between humans and the environment were an important issue and worthy of study, and many fields in the social sciences also thought the term "human ecology" was appropriate for what they were doing. The question was, was the envisioned synthetic partnership between the various contributing "human ecologies" possible? The answer soon came-not yet. A major issue of the day was that the presumptive social science partners became rapidly embroiled in something of an academic turf war as to who owned human ecology. Starting with sociology (Park \& Burgess, 1921), but soon also challenged by geography (e.g., Barrows, 1923), ethnology (e.g., Forde, 2013), and anthropology (e.g., Bews, 1935), one discipline after another claimed the field for their own. However, each field set research agendas, and interpreted and validated results purely within the theoretical frameworks of their parent discipline. Beyond finding metaphorical extensions of ecological concepts like competition, mutualism, and succession-a useful way to think about certain patterns or processes in human contexts- there was no commonality or interaction between these contested monodisciplinary forms of human ecology (Dyball et al., 2009). From the ecological perspective, there was also an alarming lack of ecology in any of them.

Despite this contest over human ecology in the social sciences, the ESA Bulletin recorded considerable time and effort spent on the promotion of human ecology within ESA from the 1940s onward. At this time, the ESA annual conference was 
jointly convened with the American Association of the Advancement of Science (AAAS). With Charles Adams and prominent ecologist Paul Sears as discussion leaders, the 1940 conference featured a session on human ecology, convened jointly with members of the AAAS Section on Social and Economic Sciences (Section K). Papers were presented on such topics as "The Relation of Man to the Natural Environment," "Agriculture as a Problem in Biological Environment," and "Man's Relation to Land." Paul Sears emerged as a strong proponent of human ecology, as documented by Cittadino (this volume). Across the next two decades, Sears contributed to ESA, building a range of activities in the name of human ecology, and becoming increasingly concerned that ecologists needed to better understand the role of culture in human decision-making as the ultimate explanation for their effects on ecosystems.

Sears became president of ESA in 1948, further enhancing the status of the human ecology approach, which he saw as fundamentally synthetic. Good landscape ecology needed to integrate with other subject areas, and work with affected committees to generate solutions to problems in terms that the community could understand. Sears saw patience, understanding, and good communication skills as crucial. Most problems were not due to "foolish individuals or bad laws, but rather [needed to be understood] in terms of the basic structure and values of society" (Sears, 1954, p. 963). His repeated concern was that human ecology was not making the contribution it could to the pressing environmental concerns of the day because it, and ecology more generally, were misunderstood, belittled, or ignored by other more prestigious sciences, and by extension the policy-makers whose ear those sciences had.

The formalization of activity in human ecology within ESA was related to the International Technical Conference on the Protection of Nature, convened in 1949 by the United Nations Educational, Scientific, and Cultural Organization (UNESCO) and the International Union of the Protection of Nature (now the International Union for the Conservation of Nature). ESA member John P. Shea presented a paper at this conference, "Human Relations: An Essential Factor in Resource Protection and Use" ("Program of the New York meeting," 1949, pp. 68-69). Following this, the United Nations (UN) and UNESCO requested ESA to provide input on the "development of an adequate methodology for Human Ecology" ("Program of the New York meeting," 1949, p. 68), to help them to pursue their conservation goals. That December, at ESA XXXIV New York, Shea proposed a resolution for "the Study and Application of the Methodology of Human Ecology by the UN and UNESCO, its Specializing Agencies, the United States Government and other cooperating agencies" ("Announcement and call for papers," 1950). Following the passing of this resolution, ESA then moved to appoint a committee to cooperate with the UN and the United States (US) government in implementing the 
resolution. This was the Committee on Human Ecology, with Shea as its founding chair. The resolution was proudly announced in a letter sent to a range of august bodies, including the US president.

The Committee on Human Ecology was involved in a range of activities through the early 1950s, commencing with a major symposium on Science and Human Values in Cleveland in 1950. Activities, including symposia and projects, were regularly reported on by the committee through the later 1950s, with the chair of the 1958 committee, George Happ, flagging a range of initiatives, including research programs, the prospect of a dedicated journal, and plans to reconstitute the committee as a formal ESA section. Happ predicted confidently that "as the values of human ecology become clearer and more important, and the techniques for the research become more developed, that research projects in human ecology will be carried on more frequently" ("Proceedings," 1959, pp. 21-23).

It is something of a mystery as to why no further evidence of activity or the existence of the Human Ecology Committee, or any other formal grouping within ESA around human ecology, can be detected from here onward. In his analysis of ESA history, Burgess (1977) wrote that "a committee on human ecology, while never pushing towards section status, has continued to function" (pp. 12-13), with the use of the present tense suggesting that the committee was still operating. However, his chart tracking the periods covered by the sections within ESA showed the Human Ecology Committee ceased to exist in the early 1960s, and no further reports from it are recorded in the Bulletin from this time. There is no doubt that individual members continued to work and publish with reference to human ecology (e.g., Paul Ehrlich and Garrett Hardin; see Borden, this volume), but from the early 1960 s, it ceased to be a term that ESA officially acknowledged. It is noteworthy that ecology itself was at this time fragmenting into numerous sub-disciplines with little agreement concerning the important and unifying themes across ecology (Neff \& Corley, 2009). Such fragmentation would not sit well with the synthetic nature of human ecology. Further, ecologists' desire to gain the respect of other sciences by refining modeling and prediction in their subfields (soon to be aided by computers) would clash with the unpredictable sociocultural aspects of human decision-making and behavior. Finally, at this time, humans were very much identified as "the problem," with many ecologists preferring to work in pristine ecosystems in which humans' pernicious presence was not felt-a preference that continues in some quarters today.

It could be argued that whether human ecology was formally acknowledged did not matter, so long as the work for which it advocated was being done, which appears to have been the case. More than a decade after the disappearance of the Human Ecology Committee from ESA's records, Sears's protégé, Paul Shepard, wrote a piece titled "Whatever Happened to Human Ecology," in which he indicated that work related to human ecology continued, but under a "myriad other names." He wrote, 
"one might conclude that the destiny of human ecology is to accept its eclectic nature. It would be impertinent to attempt to define it now so as to exclude its historical forms or its descendent and peripheral disciplines" (Shepard, 1967, p. 911). While this view may have been valid, no such undefined field of study would be acknowledged by ecological scientists as a science. Its lack of status as a science explains why human ecology had no formal presence in ESA at this time.

Borden (this volume) discusses the circumstances of the re-activation of human ecology as a section within ESA. An obvious question is, is this new manifestation likely to be any more successful than its predecessors? In the intervening 50 years, both human ecology's field of study and its means of conducting that study have changed considerably. This suggests that, in part, its success within ESA will depend on whether the science of ecology regards human ecology, as it has developed, as a legitimate methodology and valid body of knowledge. Space precludes a detailed overview of modern human ecology, which continues to take many forms, but the subject remains concerned with the ecological conditions that make life possible, blended with questions of how the human ecological system ought to be, and what constitutes living well. These questions have a normative dimension, as they involve judgments about what is good or bad; how a community should set its goals; and which of myriad means for achieving those goals are the most desirable to pursue, and in whose interest. This presents the challenge of making good decisions and policy when "facts are uncertain, values are in dispute, stakes are high, and decisions are urgent" (Functowicz \& Ravetz, 1993, p. 744). In these circumstances, the role of applied disciplinary science is decidedly limited, either individually or in multidisciplinary combinations. Good policy is fundamentally synthetic, as it involves context augmentation, blending knowledge and values from different sources. Disciplinary science is fragmentary, simplifying phenomena through context reduction. Vital as it is for describing the case under consideration, it has little to say about what should be.

ESA has set itself a guiding framework through the Earth Stewardship initiative. Through this, ESA has tasked itself with "shaping trajectories of social-ecological change at local-to-global scales to enhance ecosystem resilience and human wellbeing" (Power \& Chapin, 2009, p. 399). Human ecology is, or should be, ideally positioned to contribute to such an initiative because the initiative itself contains fundamentally normative aims of engaging with and changing society and policy. This aim demands a democratic transdisciplinary science of the kind that modern human ecology can be. Post-normal science provides very useful guides to how science might re-invent itself in this form, especially in regard to democratically informing policy decisions in complex situations. Key challenges for a post-normal human ecology include establishing the means of achieving mutual understanding between knowledge holders; enabling common understanding of the dynamics of change in complex systems that capture and intervene to affect the feedback structure 
of the system; contributing to the co-production of knowledge and decisions with stakeholders and problem owners; combining qualitative and quantitative elements equally; and developing a framework that promotes open dialogue about "what if" questions and debate on "what should be the system's goal," with an ultimate aim of facilitating discussion between stakeholders as to whether the system behavior is "what we want." A tentative approach to establishing a coherent theoretical framework that will enable human ecology to help to meet these challenges is given in Understanding Human Ecology (Dyball \& Newell, 2015), and other frameworks also exist. Whatever form it might take, if human ecology can establish itself within ESA as an operational post-normal science, then it has great potential to make its long-sought-for contribution to ESA's goals, such as those currently articulated as Earth Stewardship. This will, of course, require ESA to accept a form of postnormal science as a valid and appropriate mode of knowledge production. If such an accommodation is possible, then ecology and human ecology have the potential to contribute in a significant and greatly needed way to making the Anthropocene a just, worthwhile, and sustainable era for all humanity.

\section{References}

Adams, C. C. (1935). The relation of general ecology to human ecology. Ecology, 16(3), 316-335.

Announcement and call for papers Columbus, Ohio meeting September 11-13. (1950) Bulletin of the Ecological Society of America, 31(1), 1-32. doi.org/ $10.2307 / 20165211$

Barrows, H. H. (1923). Geography as human ecology. Annals of the Association of American Geographers, 13(1), 1-14. doi.org/10.2307/2560816

Bews, J. W. (1935). Human ecology. London: Oxford University Press.

Burgess, R. L. (1977). The Ecological Society of America: Historical data and some preliminary analyses. Oak Ridge: Ecological Society of America.

Cittadino, E. (1993). The failed promise of human ecology. In M. Shortland (Ed.), Science and nature: Essays in the history of the environmental sciences. Oxford, UK: British Society for the History of Science.

Clarke, R. (1973). Ellen Swallow: The woman who founded ecology. Chicago, IL: Follett.

Dyball, R., Borden, R. J., \& Serbser, W. (2009). New directions in human ecology education. In P. Lopes \& A. Begossi (Eds.), Current trends in human ecology (pp. 250-272). Newcastle-Upon-Tyne: Cambridge Scholars. 
Dyball, R., \& Newell, B. (2015). Understanding human ecology: A systems approach to sustainability. Abingdon, Oxfordshire: Routledge.

Fischer, J., Dyball, R., Fazey, I., Gross, C., Dovers, S., Ehrlich, P. R., ... Borden, R. J. (2012). Human behavior and sustainability. Frontiers in Ecology and the Environment, 10(3), 153-160.

Forde, C. D. (2013). Habitat, economy and society: A geographical introduction to ethnology. Abingdon, Oxfordshire: Routledge.

Funtowicz, S. O., \& Ravetz, J. R. (1991). A new scientific methodology for global environmental issues. In R. Costanza (Ed.), Ecological economics: The science and management of sustainability. New York, NY: Columbia University.

Funtowicz, S. O., \& Ravetz, J. R. (1993). “Science for the post-normal age.” Futures, 25(7), 739-755.

Lubchenco, J. (2017). Environmental science in a post-truth world. Frontiers in Ecology and the Environment, 15(1), 3. doi.org/10.1002/fee.1454

Neff, M., \& Corley, E. (2009). 35 years and 160,000 articles: A bibliometric exploration of the evolution of ecology. Scientometrics, 80(3), 657-682. doi.org/ 10.1007/s11192-008-2099-3

Park, R. E., \& Burgess, E. (1921). Introduction to the science of sociology. Chicago, IL: Chicago University Press.

Power, M. E., \& Chapin, F. S. (2009). Planetary stewardship. Frontiers in Ecology and the Environment, 7(8), 399. doi.org/10.1890/1540-9295-7.8.399

Proceedings. (1959). Bulletin of the Ecological Society of America, 40(1), 10-29. doi.org/10.2307/20165499

Program of the New York meeting with abstracts of papers, thirty-fourth annual meeting of the Ecological Society of America with the American Association for the Advancement of Science, the Botanical Society of America, the American Society of Limnology and Oceanography, the American Society of Zoologists and the American Society of Naturalists, New York City, Tue. (1949). Bulletin of the Ecological Society of America, 30(4), 45-72. doi.org/10.2307/20165209

Ravetz, J. (1997). The science of "what-if?" Futures, 29(6), 533-539. doi.org/ $10.1016 /$ s0016-3287(97)00026-8

Ravetz, J. (2006). Post-normal science and the complexity of transitions towards sustainability. Ecological Complexity, 3(4), 275-284. doi.org/10.1016/j. ecocom.2007.02.001 
Sanderson, J. B. (1893). On the origin of biology and its relation to the other branches of natural science. British Medical Journal, 2(1707), 613-617. doi.org/ 10.1136/bmj.2.1707.613

Sears, P. (1954). Human ecology: A problem in synthesis. Science, 120(3128), 959-963. doi.org/10.1126/science.120.3128.959

Shelford, V. E. (1917). The ideals and aims of the Ecological Society of America. Bulletin of the Ecological Society of America, 1(3), 1-8. doi.org/10.1890/00129623-96.1.12

Shepard, P. (1967). Whatever happened to human ecology? BioScience, 17(12), 891-911. doi.org/10.2307/1293928

Worster, D. (1977). Nature's economy: The roots of ecology. San Francisco, CA: Sierra Club Books. 
This text is taken from Human Ecology Review, Volume 23, Number 2, 2017, published 2017 by ANU Press, The Australian National University, Canberra, Australia.

dx.doi.org/10.22459/HER.23.02.2017.02 